\title{
Hot Corrosion Behavior of Sol-Gel Nano Structured Zirconia Coated 9Cr1Mo Ferritic Steel in Alkali Metal Chlorides and Sulphates Deposit Systems at High Temperatures
}

\author{
Gazala Ruhi, O. P. Modi, I. B. Singh* \\ Council of Scientific and Industrial Research, Advance Materials and Process Research Institute (AMPRI), Bhopal, India. \\ Email: gazala4u2002@yahoo.co.in,om_prakashmodi@yahho.com, *ibsingh58@yahoo.com
}

Received November $22^{\text {nd }}, 2012$; revised December $25^{\text {th }}, 2012$; accepted January $3^{\text {rd }}, 2013$

\begin{abstract}
Fused salt accelerated hot corrosion is quite common in gas turbines, fossil fuelled devices, waste inclinators, pyrochemical systems, etc. Presence of fused salt on metal surface dissolves their existing oxide layer. This results in an increase in oxidation rate of the metal. Since, zirconia coating is well recognized for corrosion protection under high temperature oxidative environment, we have developed zirconia coating on 9Cr1Mo ferritic steel and their oxidation performance was evaluated in $\mathrm{LiCl}-\mathrm{NaCl}$ and $\mathrm{Na}_{2} \mathrm{SO}_{4}-\mathrm{K}_{2} \mathrm{SO}_{4}$ salts deposit system in air atmosphere at $650^{\circ} \mathrm{C}$ and $850^{\circ} \mathrm{C}$, respectively. Before coating development, zirconium based sol was synthesized using zirconium (IV) propoxide as a precursor. Oxidation test results indicated that the zirconia coated specimens shows more than two times higher corrosion resistance in $\mathrm{LiCl}-\mathrm{NaCl}$ and three time higher corrosion resistance in $\mathrm{Na}_{2} \mathrm{SO}_{4}-\mathrm{K}_{2} \mathrm{SO}_{4}$ salt deposit, respectively.
\end{abstract}

Keywords: Sol-Gel Zirconia Coating; 9Cr1Mo Ferritic Steel; Hot Corrosion; Salt Deposits

\section{Introduction}

Presence of alkali metal salts like sulphates, chlorides containing deposits make the environment more aggressive and oxidizing at high temperature. Once these salt deposits melt at their melting temperature, the oxidation of metals becomes abruptly high due to the starts of molten salts or fused salt induced hot corrosion. Fused salt accelerated hot corrosion is quite common in gas turbines, fossil fuelled devices, waste inclinators, pyrochemical systems etc. [1,2]. To control such types of corrosion attack, zirconia based coatings could be preferred, as it posses superior hardness, low thermal conductivity, good mechanical and chemical durability and high temperature properties. In addition to this, the thermal expansion coefficient of zirconia matches with many of the metals. Due to this, coatings are less susceptible towards cracking or spalling.

A number of techniques like plasma deposition, thermal spraying, physical vapor deposition etc. have been used by various researchers to produce zirconia coatings on different substrates $[3,4]$. However, requirement of

"Corresponding author. high temperature and pressure in the development of coating by these methods, are the main drawbacks for the coating development. Coatings produced by these methods are porous in nature. Rather, recently developed sol-gel based zirconia coatings have been reported to improve the high temperature oxidation behavior of various steels [5-7]. Li and co-workers [7] have developed zirconia coating by using zirconium-n-propoxide as a precursor material through sol-gel route. In another work, use of acetyl acetone and ethyl acetoacetate are reported to reduce hydrolysis rate of the precursor and improve the homogeneity of the coating $[8,9]$. Apart from this, several studies have been carried out on the corrosion protection of stainless steel by sol-gel zirconia coatings [10-15]. Nano structured sol-gel zirconia coatings have been developed on aluminium, stainless steel and glass substrates [16]. Oxidation resistance of sol-gel zirconia coating have been studied well in air/gaseous oxidation system. However, no report is available in literature related to their hot corrosion studies in salt deposits containing oxidative environment. In the present work solgel nano structured zirconia coatings have been developed on low chromium $9 \mathrm{Cr} 1 \mathrm{Mo}$ ferritic steel and their 
performance evaluation is made in $\mathrm{LiCl}-\mathrm{NaCl}$ and $\mathrm{Na}_{2} \mathrm{SO}_{4}-\mathrm{K}_{2} \mathrm{SO}_{4}$ salt deposits in furnace air atmosphere at $650^{\circ} \mathrm{C}$ and $850^{\circ} \mathrm{C}$, respectively.

\section{Aim of the Present Work}

The aim of the present work was to synthesize zirconium based hydroxyl sol using non aqueous zirconium (IV)-npropoxide as precursor material which can be coated on 9 Cr1Mo ferritic steel for oxidation and hot corrosion protection purpose.

\section{Experimental Work}

\subsection{Synthesis of Zirconia Sol}

Zirconia sol has been prepared by taking zirconium(IV)n-propoxide as a precursor. $10 \mathrm{ml}$ volume of precursor was diluted with $100 \mathrm{ml}$ of n-propanol with continuous stirring. Thereafter, acetyl acetone was added within a few minutes of the addition of the n-propanol. A few drops of water were also added to the solution and the resultant solution was stirred up to $4 \mathrm{hrs}$ with proper mixing. Once, solution becomes miscible the stirring was stopped and resultant solution was used for coating development. The viscosity of the synthesized sol was measured using Brookfield make rheometer.

\subsection{Coatings Development}

The 9 Cr1Mo ferritic steel sheet was cut to a dimension of $30 \mathrm{~mm} \times 18 \mathrm{~mm} \times 3 \mathrm{~mm}$ for oxidation/hot corrosion test under air/fused salt system. The cut samples were metallographically polished by grinding them with emery paper of 120, 600, 800 grit size followed by mirror polish with alumina suspension (size $3 \mu \mathrm{m}$ ). The metallographically polished specimens were degreased properly with acetone. In the next step polished specimens were kept in concentrated nitric acid for few minute to roughen the surface for a purpose of increased the coating adherence. Afterwards, the synthesized zirconia sol was coated on the polished substrate through dip coating technique with a constant withdrawal speed of $1 \mathrm{~cm} / \mathrm{sec}$ (approx). The coated specimens were dried in air for 10 minutes. Further, the coated specimens were heated at $300^{\circ} \mathrm{C}$ and kept at the desired temperature for half an hour. The heat treatment temperature was then raised to $600^{\circ} \mathrm{C}$ for complete sintering of the coatings.

FTIR analysis of the coatings was carried out using FTIR (Model Nicolet 5700) in a frequency range of 4000 - $500 \mathrm{~cm}^{-1}$ analyze the presence of different functional groups in the gel. The phase analysis of the uncoated and sol-gel coated specimens were performed by X-Ray Diffraction method using a computer controlled X-Ray diffractometer (Bruker, D8 Model)under $\mathrm{CuK} \alpha$ radiation.
The microstructure examination of the oxidized specimens was performed with the help of Scanning Electron Microscope (JEOL, Japan make JSM 5600). Cross-sectional analysis of the oxidized specimens was examined after cutting it carefully with the help of high precision diamond cutting wheel in the presence of a coolant. VEECO make Nano Scope AFM was employed for measuring the particle size of the sol-gel coatings and surface roughness of the coated surface.

\subsection{Oxidation Test}

The weight gain of the uncoated and coated test specimens was measured in air/salt deposit at $650^{\circ} \mathrm{C}$ in $\mathrm{NaCl}+$ $\mathrm{LiCl}$ and at $850^{\circ} \mathrm{C}$ in $\mathrm{Na}_{2} \mathrm{SO}_{4}+\mathrm{K}_{2} \mathrm{SO}_{4}$ salt deposit system. The weight gain of the test specimens were recorded at regular intervals of time using a Mettler balance. For conducting oxidation tests in air/salt deposit environment an equimolar mixture of $\mathrm{NaCl}+\mathrm{LiCl}$ and $\mathrm{Na}_{2} \mathrm{SO}_{4}+$ $\mathrm{K}_{2} \mathrm{SO}_{4}$ was prepared. The coated and uncoated steel specimens were dipped in the saturated solution of the above mentioned salt mixture. The salt coated specimens were dried with hot air blower and placed in the furnace for oxidation tests. The temperature of the furnace was maintained at $650^{\circ} \mathrm{C} \pm 5^{\circ} \mathrm{C}$ for $\mathrm{NaCl}+\mathrm{LiCl}$ mixture, which is above their melting point [17]. The oxidation temperature in the case of sulphate mixture was maintained at $850^{\circ} \mathrm{C} \pm 5^{\circ} \mathrm{C}$, which is around melting point of the salt mixture [18]. Weight gain of the test specimens was measured after regular intervals by removing the specimens from the furnace. Similarly, sol-gel coated specimens were weighted and kept for oxidation test under identical conditions as in case of uncoated specimens. After removing from the furnace, oxidized specimens were cooled, cleaned and reweighted to measure actual weight change. The test specimens are designated as 1) CS for coated steel; and 2) BS for uncoated steel in text and figures.

\section{Results and Discussion}

\subsection{Synthesis of Zirconia Sol}

The detailed mechanism of synthesis of zirconia sol is as follows.

Since zirconium-n-propoxide is miscible in the n-propanol, it exists as a dimeric molecule as shown [19].

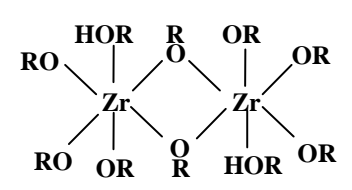

The addition of acetyle acetone as chelating agent, the bidentate ligand transform in to a complex structure [20] as 


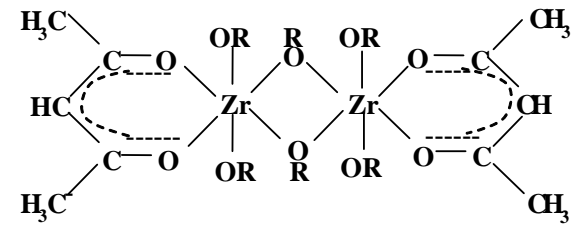

The terminal -OR groups is displaced by -OH after hydrolyzing in water, resulting in the formation of folwing complex

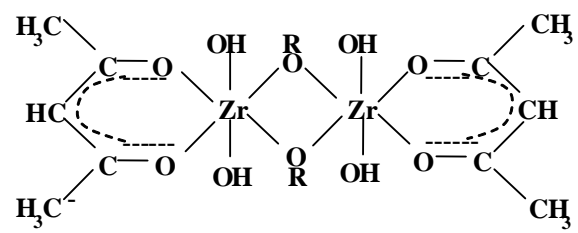

The exchange of terminal -OH groups with the -OR groups takes place because of the strong bridging ability of -OH groups.

Finally a linear polymer of a general formula $\mathrm{Zr}(\mathrm{acac})$ $(\mathrm{OH})$ is formed after condensation of the smaller units given as.

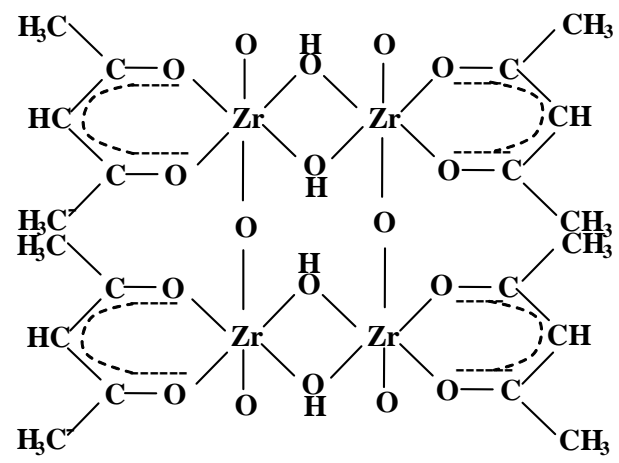

The viscosity of zirconia sol was measured at a constant shear rate of $123 \mathrm{~s}^{-1}$ for $300 \mathrm{~s}$ (seconds). The measured viscosity was found to be $1.36 \mathrm{mPas}$ whereas $\mathrm{pH}$ of the synthesized sol was measured as 9.3 .

\subsection{Coating Characterization}

The FTIR spectrum of $\mathrm{ZrO}_{2}$ coated surface is shown in Figure 1. The exhibition of a broad absorbance band between the spectral range of $3600-3800 \mathrm{~cm}^{-1}$ is due to the stretching mode of vibration of chemically bonded -OH groups. The next peak observed at $2920.8 \mathrm{~cm}^{-1}$ is mainly due to the $\mathrm{C}-\mathrm{H}$ stretching of alkyl groups present in the gel.

Observation of another peak at considerably high intensity of $2339.4 \mathrm{~cm}^{-1}$ could be due to the presence of $\mathrm{C}-\mathrm{O}$ bonds. The subsequent peaks observed at 1595 and $1510 \mathrm{~cm}^{-1}$ are due to the stretching vibration of $\mathrm{C}=\mathrm{C}$ and $\mathrm{C}=\mathrm{O}$ groups, respectively indicating the chelation of

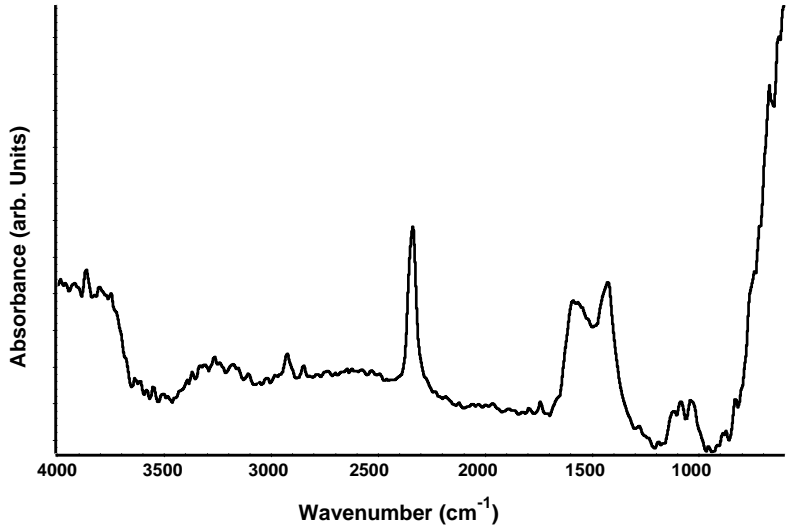

Figure 1. FTIR spectrum of the coated specimen.

acetylacetone groups with zirconium [21]. Further, the peaks observed at 1084 and $1038.7 \mathrm{~cm}^{-1}$ demonstrate $\mathrm{Zr}-\mathrm{O}-\mathrm{C}$ and $\mathrm{Zr}-\mathrm{O}$ stretching mode of vibration. The immergence of a small peak at $720 \mathrm{~cm}^{-1}$ demonstrates the characteristic of $\mathrm{Zr}-\mathrm{O}-\mathrm{Zr}$ bands [22]. Above observations demonstrated that zirconia phase is formed after sintering the sol-gel specimens at the above mentioned temperatures.

Figure 2 demonstrates the X-ray diffractograph of the sol-gel zirconia coated steel specimen. The observation of high intensity peaks of $2 \theta$ value at $41.64^{\circ}, 44.66^{\circ}$ and $65.02^{\circ}$ are mainly due to the base metal $(\alpha-\mathrm{Fe})$. Another peaks occur at $38.01^{\circ}$ and $39.68^{\circ}$ is related to the presence of iron zirconia mixed phase $\left(\mathrm{Zr}_{6} \mathrm{Fe}_{3} \mathrm{O}\right) \mathrm{Fe}$. Observations of very low intensity peaks at $26^{\circ}$ and $52.21^{\circ}$ demonstrate the presence of monoclinic phase of zirconia.

The thickness of the coating was estimated around 5 $7 \mu \mathrm{m}$ through weight measurement of the specimens before and after coating development. Figure 3 depicts the AFM micrographs of the sol-gel zirconia coated substrates. The AFM micrograph reveals a surface structure free from cracks and voids. Because of the uneven surface of the substrate, the coating present in the grooves (dark areas) is not clearly visible in the micrographs. The average size of the zirconia particles was determined as $13-15 \mathrm{~nm}$ in size. Agglomeration of zirconia particles (size $\sim 40 \mathrm{~nm}$ ) was noticed on certain regions of the coated surface.

\subsection{Oxidation Kinetics}

Following Equation (1) is used for the elucidation of rate constant;

$$
(\Delta \mathrm{W} / \mathrm{A})^{2}+\mathrm{C}=\mathrm{K} \cdot \mathrm{t}
$$

where $(\Delta \mathrm{W} / \mathrm{A})^{2}$ is square of weight gain per unit area, $t$ is the time of exposure and $\mathrm{K}$ is rate constant. The value of $\mathrm{K}$ was measured by dividing the square of weight gain with time of exposure. The measured values of rate con- 


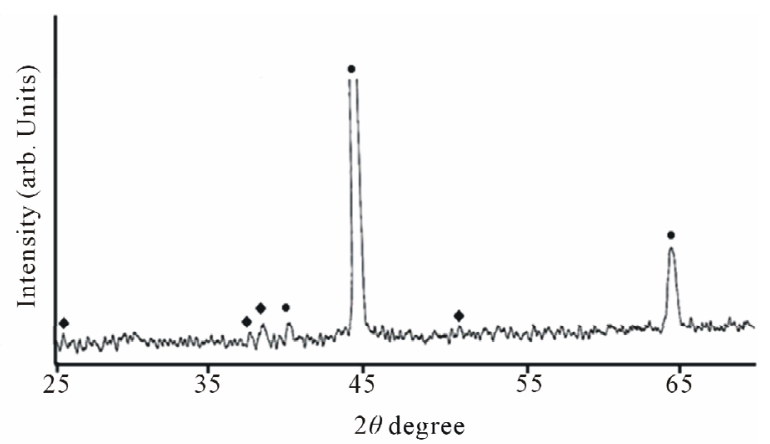

Figure 2. XRD spectrum of coated specimen.

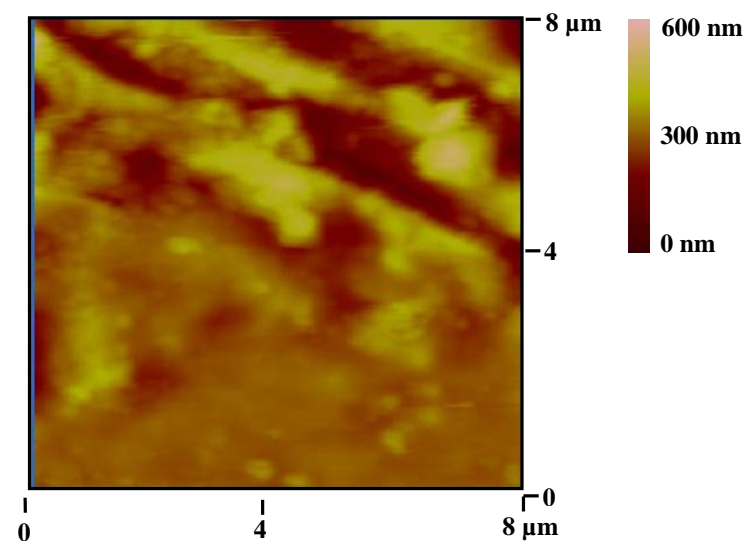

Figure 3. AFM micrograph of zirconia coated 9Cr1Mo steel specimen.

stant are expressed in $\mathrm{mg}^{2} / \mathrm{cm}^{4}$ min. Following Arrhenius equation (Equation (2)) was used for the elucidation of the values of activation energy;

$$
\mathrm{K}=\mathrm{Ae}^{-\mathrm{Ea} / \mathrm{RT}}
$$

where $E_{a}$ is the activation energy, $R$ is gas constant and $T$ is temperature.

Based on the above kinetic Equation (1), the square of weight gain vs time curves obtained for the coated and uncoated specimens in $\mathrm{NaCl}+\mathrm{LiCl}$ and $\mathrm{Na}_{2} \mathrm{SO}_{4}+\mathrm{K}_{2} \mathrm{SO}_{4}$ system at $600^{\circ} \mathrm{C}$ and $850^{\circ} \mathrm{C}$, are shown in Figures $\mathbf{4}$ and 5 , respectively.

It can be seen that oxidation kinetics posses parabolic trend for the uncoated specimen. In the beginning, a fast oxidation rate is observed which becomes almost constant after 6 hrs of oxidation in $\mathrm{NaCl}+\mathrm{LiCl}$ salt. In case of $\mathrm{Na}_{2} \mathrm{SO}_{4}+\mathrm{K}_{2} \mathrm{SO}_{4}$ system, a sharp increase of oxidation kinetics was found till $18 \mathrm{hrs}$ of exposure. Afterwards, the oxidation rate was slowed down.

The fused salt layer causes dissolution of the iron oxide and chromium rich iron oxide layer present on the surface and further reprecipitates at other sites where the solubility gradient is less $[18,23]$. The reprecipitated oxide scale is non protective in nature and causes an easy

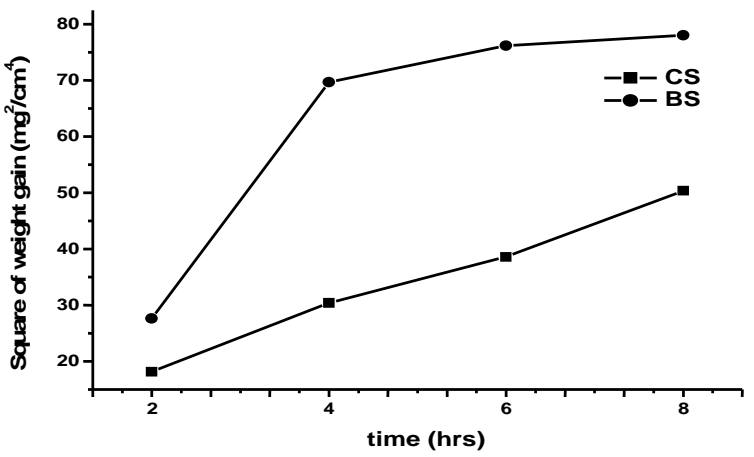

Figure 4. Square of weight gain vs time curves for the zirconia coated and uncoated 9Cr1Mo steel specimens oxidized in $\mathrm{NaCl}+\mathrm{LiCl}$ salt at $650^{\circ} \mathrm{C}$ for $8 \mathrm{hrs}$.

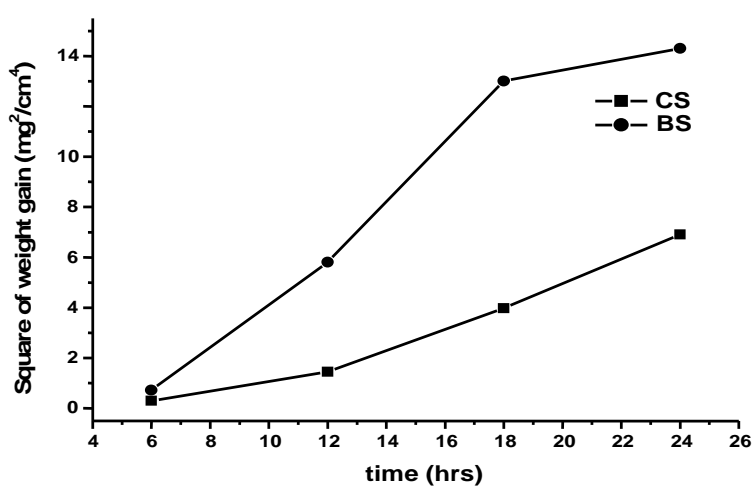

Figure 5. Square of weight gain vs time curves for the zirconia coated and uncoated 9Cr1Mo steel specimens oxidized in $\mathrm{Na}_{2} \mathrm{SO}_{4}+\mathrm{K}_{2} \mathrm{SO}_{4}$ salt at $850^{\circ} \mathrm{C}$ for $24 \mathrm{hrs}$.

penetration of fused salt through the pores and cracks of the scale.

The coated specimen showed a regular increase of weight with respect to the exposure time. But, the weight gain measured for the sol-gel zirconia coated specimen seemed to be significantly lower than that of weight gain measured for the uncoated specimen. The rate constants and activation energies derived from the oxidation curves are summarized in Tables $\mathbf{1}$ and 2, respectively. The rate constant of the uncoated specimen occurred more than two times higher in $\mathrm{NaCl}+\mathrm{LiCl}$ system whereas, more than three times higher rate occurred in the $\mathrm{Na}_{2} \mathrm{SO}_{4}+$ $\mathrm{K}_{2} \mathrm{SO}_{4}$ system. This was reconfirmed by deriving the activation energies of the coated and uncoated oxidized specimens. A appreciably higher activation energy is derived for the coated specimen as compared to uncoated specimen in both systems. Occurrence of three times higher activation energy of the oxidized specimen in $\mathrm{Na}_{2} \mathrm{SO}_{4}+\mathrm{K}_{2} \mathrm{SO}_{4}$ system as compared to $\mathrm{NaCl}+\mathrm{LiCl}$ system indicate the less oxidative nature of $\mathrm{Na}_{2} \mathrm{SO}_{4}+$ $\mathrm{K}_{2} \mathrm{SO}_{4}$ system. The above observations clearly demonstrate that the zirconia coating acts as a protective barrier layer up to certain extent and improves the hot corrosion 
Table 1. Rate constants measured for coated and uncoated 9Cr1Mo steel specimens in air/salt environment.

\begin{tabular}{ccc}
\hline $\begin{array}{c}\text { Substrate } \\
\text { (9Cr1Mo steel) }\end{array}$ & \multicolumn{2}{c}{ Rate constant, $\mathbf{K}\left(\mathbf{m g}^{2} / \mathbf{c m}^{4} \cdot \mathbf{m i n}\right)$} \\
\cline { 2 - 3 } & $\mathbf{N a C l}+\mathbf{L i C l}$ & $\mathbf{N a}_{2} \mathbf{S O}_{4}+\mathbf{K}_{2} \mathbf{S O}_{4}$ \\
\hline Coated & $1.22 \times 10^{-1}$ & $2.82 \times 10^{-3}$ \\
Uncoated & $2.36 \times 10^{-1}$ & $7.64 \times 10^{-3}$ \\
\hline
\end{tabular}

Table 2. Activation energies measured for coated and uncoated 9Cr1Mo steel specimens in air/salt environment.

\begin{tabular}{ccc}
\hline $\begin{array}{c}\text { Substrate } \\
\text { (9Cr1Mo steel) }\end{array}$ & \multicolumn{2}{c}{ Activation Energy, $\mathbf{E}_{\mathbf{a}}(\mathbf{K J} / \mathbf{m o l e})$} \\
\cline { 2 - 3 } & $\mathbf{N a C l}+\mathbf{~ L i C l}$ & $\mathbf{N a}_{\mathbf{2}} \mathbf{S O}_{4}+\mathbf{K}_{\mathbf{2}} \mathbf{S O}_{4}$ \\
\hline Coated & 3.19 & 10.337 \\
Uncoated & 3.045 & 10.189 \\
\hline
\end{tabular}

of the base metal in both systems. Since equimolar $\mathrm{NaCl}$ $+\mathrm{LiCl}$ salt mixture melt at $650^{\circ} \mathrm{C}$ [17] and equimolar $\mathrm{Na}_{2} \mathrm{SO}_{4}+\mathrm{K}_{2} \mathrm{SO}_{4}$ salt system melt around $850^{\circ} \mathrm{C}$ [18], presence of fused salt layer at the exposed surfaces enhances their oxidation rate appreciably. Presence of fused salt flux dissolves the existing oxide layer present on the metal. This leads an increased oxidation kinetics of the uncoated specimen in the beginning itself. Whereas, the presence of zirconia coating act a barrier layer between metal and fused salt and controls the inward diffusion of oxide ions and outward migration of oxidized metal ions up to a certain level. This is the reason that a relatively less oxidation rate is observed for the coated specimens as compared to the uncoated specimen.

\subsection{Microstructural Examination}

The cross-sectional views the uncoated and coated specimens oxidized in $\mathrm{NaCL}+\mathrm{LiCl}$ salt mixture are shown in Figures 6(a) and (b), respectively. A loosely bonded oxide scale of around $70-80 \mu \mathrm{m}$ in thickness with the presence of cracks and voids is seen on the surface of the uncoated specimen. A severe surface damage can be seen from the micrograph. The cross-sectional view of the coated specimen shows the presence of somewhat more compact scale without any crack. Thickness of the oxide scale is comparatively less than that of the thickness of uncoated specimen. This suggests that comparatively less oxidation occurred for the coated specimen in $\mathrm{NaCl}+$ $\mathrm{LiCl}$ salt mixture.

The cross-sectional views of the uncoated and coated specimens exposed in $\mathrm{Na}_{2} \mathrm{SO}_{4}+\mathrm{K}_{2} \mathrm{SO}_{4}$ at $850^{\circ} \mathrm{C}$ for 24 hrs are shown in Figures 7(a) and (b), respectively. The cross-sectional micrograph of the uncoated specimen reveals a loosely bonded outer scale of thickness around

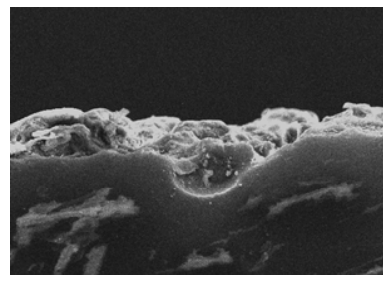

(a)

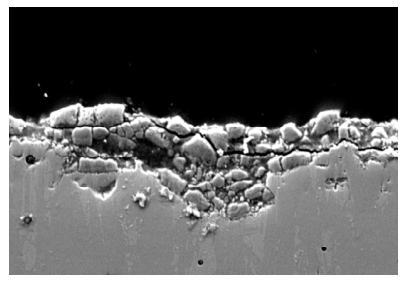

(b)
Figure 6. Cross-sectional views of (a) Uncoated and (b) Zirconia coated 9Cr1Mo steel specimens oxidized in $\mathrm{NaCl}+$ $\mathrm{LiCl}$ salt at $650^{\circ} \mathrm{C}$ for $8 \mathrm{hrs}$.

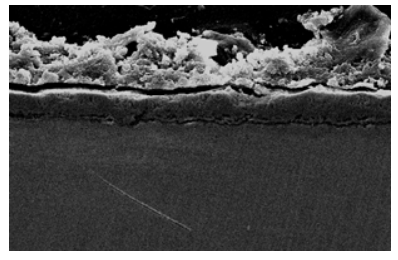

(a)

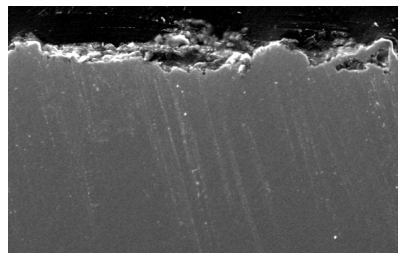

(b)
Figure 7. Cross-sectional views of (a) Uncoated and (b) Zirconia coated $9 \mathrm{Cr} 1 \mathrm{Mo}$ steel specimens oxidized in $\mathrm{Na}_{2} \mathrm{SO}_{4}+$ $\mathrm{K}_{2} \mathrm{SO}_{4}$ salt at $850^{\circ} \mathrm{C}$ for 24 hrs.

$50 \mu \mathrm{m}$ covering an inner layer of thickness around $35 \mu \mathrm{m}$. Unlike the presence of middle scale in uncoated specimen, no such oxide layer is seen in the oxidized coated specimen. This further evidences the occurrence of less oxidation reaction to the coated specimens.

\section{Conclusions}

- Sol-gel based zirconia sol was synthesised successsively which was found to be quite effective for the development of nano structured zirconia coating on 9Cr1Mo ferritic steel surfaces. Presence of nano structured zirconia coating is confirmed by AFM analysis. The XRD of the coated specimen reveals the presence of monoclinic phase of zirconia in the coating. The FTIR plot of the zirconia coated specimen further confirms the $\mathrm{Zr}-\mathrm{O}-\mathrm{Zr}$ bonds of the zirconia attached with the iron of the base metal.

- The oxidation kinetics measurement of the sol-gel coated and uncoated specimens exhibits the occurrence of a two times lower oxidation rate in $\mathrm{NaCl}+$ $\mathrm{LiCl}$ at $650^{\circ} \mathrm{C}$ and more than three times lower oxidation rate in $\mathrm{Na}_{2} \mathrm{SO}_{4}+\mathrm{K}_{2} \mathrm{SO}_{4}$ salt system at $850^{\circ} \mathrm{C}$.

- The microstructural studies evidenced the presence of somewhat thin oxide scale on the oxidised coated specimen as compared to oxidized uncoated specimens. Scale forms on the oxidized uncoated specimens was found to be with full of cracks and voids that enhances the inward diffusion of oxide ion and outward migration of oxidised metal ions.

- The oxidation rate measurement indicates that $\mathrm{NaCl}+$ 
$\mathrm{LiCl}$ salt system is more than three times higher oxidative as compared to $\mathrm{Na}_{2} \mathrm{SO}_{4}+\mathrm{K}_{2} \mathrm{SO}_{4}$ salt system.

\section{REFERENCES}

[1] J. Stringer, "High Temperature Corrosion of Aerospace Alloys," AGARD-AG, 1975, p. 200.

[2] J. Stringer, "Hot Corrosion of High-Temperature Alloys," Materials Research, Vol. 7, 1977, pp. 477-509. doi:10.1146/annurev.ms.07.080177.002401

[3] Y. H. Sohn, R. R. Biederman and R. D. Sisson, "Microstructural Development in Physical Vapour-Deposited Partially Stabilized Zirconia Thermal Barrier Coatings," Thin Solid Films, Vol. 250, No. 1-2, 1994, p. 201. doi:10.1016/0040-6090(94)90155-4

[4] G. M. Ingo, "Origin of Darkening in $8 \mathrm{wt} \%$ Yttria-Zirconia Plasma-Sprayed Thermal Barrier Coatings," Journal of the American Ceramic Society, Vol. 74, No. 2, 1991, pp. 381-386. doi:10.1111/j.1151-2916.1991.tb06891.x

[5] A. Nazeri and S. B. Qadri, "Alumina-Stabilized Zirconia Coatings for High-Temperature Protection of Turbine Blades," Surface and Coatings Technology, Vol. 86-87, Pt. 1, 1996, pp. 166-169. doi:10.1016/S0257-8972(96)03025-3

[6] Y. S. Baron, A. Ruiz and G. Navas, "High Temperature Oxidation Resistance of $1.25 \mathrm{cr}-0.5 \mathrm{mo}$ wt $\%$ Steels by Zirconia Coating," Surface and Coatings Technology, Vol. 202, No. 12, 2008, pp. 2616-2622. doi:10.1016/j.surfcoat.2007.09.038

[7] H. Li, K. Liang, L. Mei, S. Gu and S. Wang, "Oxidation Protection of Mild Steel by Zirconia Sol-Gel Coatings," Materials Letters, Vol. 51, No. 4, 2001, pp. 320-324. doi:10.1016/S0167-577X(01)00311-1

[8] C. Sanchez, J. Livage, M. Henry and F. Babonneau, "Chemical Modification of Alkoxide Precursors," Journal of Non-Crystalline Solids, Vol. 100, No. 1-3, 1988, pp. 6576. doi:10.1016/0022-3093(88)90007-5

[9] M. Guglielmi and G. Carturan, "Precursors for Sol-Gel Preparations," Journal of Non-Crystalline Solids, Vol. 100, No. 1-3, 1988, pp. 16-30. doi:10.1016/0022-3093(88)90004-X

[10] K. Lzumi, M. Murakami, T. Deguchi and A. Morita, "Zirconia Coating on Stainless Steel Sheets from Organozirconium Compounds," Journal of the American Ceramic Society, Vol. 72, No. 8, 1989, pp. 1465-1468. doi:10.1111/j.1151-2916.1989.tb07677.x

[11] S. Hirai, K. Shimakage and S. Aizawa, "Alkaline Corrosion Resistance of Anodized Aluminum Coated with Zir- conium Oxide by a Sol-Gel Process," Journal of the American Ceramic Society, Vol. 81, No. 12, 1998, pp. 3087-3092. doi:10.1111/j.1151-2916.1998.tb02742.x

[12] R. Dimaggio, L. Fedrizzi, S. Rossi and P. Scardi, "Dry and Wet Corrosion Behaviour of AISI 304 Stainless Steel Coated by Sol-Gel $\mathrm{ZrO}_{2} \mathrm{CeO}_{2}$ Films," Thin Solid Films, Vol. 286, No. 1-2, 1996, pp. 127-135. doi:10.1016/S0040-6090(95)08515-7

[13] M. Atik, C. P. Kha, P. Delimaneto, L. A. Avaca, M. A. Aegerter and J. Zarzycki, "Protection of 316L Stainless Steel by Zirconia Sol-Gel Coatings in $15 \% \mathrm{H}_{2} \mathrm{SO}_{4}$ Solutions," Journal of Materials Science Letters, Vol. 14, No. 3, 1995, pp. 178-181. doi:10.1007/BF00318248

[14] M. Shane and M. L. Mecartney, "Sol-Gel Synthesis of Zirconia Barrier Coatings," Journal of Materials Science, Vol. 25, No. 3, 1990, pp. 1537-1544. doi:10.1007/BF01045347

[15] G. Ehrhart, B. Capoen, O. Robbe, Ph. Boy, S. Turrell and M. Bouazaoui, "Structural and Optical Properties of nPropoxide Sol-Gel Derived $\mathrm{ZrO}_{2}$ Thin Films," Thin Solis Films, Vol. 496, No. 2, 2006, pp. 227-233. doi:10.1016/j.tsf.2005.08.309

[16] K. W. Tenze, K. Valle, L. Bianchi, P. Belleville and N. Caron, "Nanostructured Zirconia Coatings Processed by PROSOL Deposition," Surface and Coatings Technology, Vol. 202, No. 18, 2008, pp. 4349-4354. doi:10.1016/j.surfcoat.2008.04.008

[17] K. H. Yoon, Y. S. Cho and D. H. Kang, "Molten Salt Synthesis of Lead-Based Relaxors," Journal of Materials Science, Vol. 33, No. 12, 1998, pp. 2977-2984. doi:10.1023/A:1004310931643

[18] J. Stringer, High Temperature Technologies, Vol. 3, 1985, p. 119.

[19] D. C. Bradley, R. C. Mehrotra and D. P. Gaur, "Metal Alkoxides," Academic Press, New York, 1978, p. 27.

[20] U. B. Saxena, A. K. Rai, V. K. Mathur and R. C. Mehrotra, Journal of the Chemical Society, Vol. A, 1970, p. 904.

[21] R. Brenter and A. Gagnaire, "Densification and Aging of $\mathrm{ZrO}_{2}$ Films Prepared by Sol-Gel," Thin Solid Films, Vol. 392, No. 1, 2001, pp. 142-148. doi:10.1016/S0040-6090(01)01009-4

[22] Q. F. Quinson, G. Chino, M. D. Becdelievre, L. Guizar and H. Brunel, Journal of Materials Science, Vol. 31, 1996, p. 5.

[23] R. A. Rapp and K. S. Goto, 2nd International Symposium, Molten Salts, J. Braunstein, Ed., The Electrochemical Society, New Jersey, 1981, p. 81. 